\title{
First Approval of Generic Mometasone Furoate Nasal Suspension Spray in Japan: Similarities and Differences Between Japan and the USA
}

Ryosuke Kuribayashi ( $\sim$ kuribayashi-ryosuke@pmda.go.jp )

PMDA https://orcid.org/0000-0002-6778-7114

Miho Kasuga

PMDA

Kimika Kuwana

PMDA

Toru Yamaguchi

PMDA

\section{Short Report}

Keywords: First approval, Generic, Mometasone furoate suspension nasal spray, Bioequivalence study, Japan

Posted Date: January 18th, 2022

DOI: https://doi.org/10.21203/rs.3.rs-1200976/v1

License: (c) (i) This work is licensed under a Creative Commons Attribution 4.0 International License. Read Full License 


\section{Abstract}

The Ministry of Health, Labour and Welfare (MHLW) in Japan approved the first generic version of Nasonex in February 2018. The Pharmaceuticals and Medical Devices Agency requires in vitro, pharmacokinetic, and pharmacodynamic or clinical endpoint data to approve generic nasal spray drug products. However, the MHLW has not published basic principle for approving nasal generic drug products. Therefore, this article summarizes the data used for the approval of the first generic Nasonex based on publicly available data. Additionally, we compare the bioequivalence evaluations regarding the human studies based on the generic version of Nasonex between Japan and the USA.

\section{Key Points}

This article summarizes the data used for the first approval of a generic mometasone furoate nasal suspension spray based on public data.

The PMDA generally requires in vitro, pharmacokinetic, and pharmacodynamic or clinical endpoint data for the approval of a generic drug and for bioequivalence evaluations of any generic nasal suspension spray.

This article compares the bioequivalence evaluations based on the generic mometasone furoate nasal suspension spray between Japan and the USA.

\section{Introduction}

In February 2018, the Ministry of Health, Labour and Welfare (MHLW) in Japan approved the first generic version of Nasonex Nasal Spray at a dosage of $50 \mu \mathrm{g}$ in products containing 56 or 112 sprays. This product was developed by Toko Yakuhin Kogyo Co. Ltd. and emits 50 g of mometasone per spray and was approved for the same indications as the original products (i.e., allergic rhinitis for adult and pediatric patients). This generic product has different pharmaceutical properties compared to the original product including:

1) The use of a gel base with a higher viscosity that reduces the dripping and/or leakage of the drug solution into the throat after spraying.

2) The use of an upper exhaust pressure airless spray container allows for the nasal spray to be used and sprayed from any angle.

3) A uniform suspension of the drug product was used which makes shaking before use unnecessary.

The bioequivalence (BE) data from the pharmacokinetic $(\mathrm{PK})$ and clinical endpoint studies are available in the package insert and publication documents $[1,2]$. The Pharmaceuticals and Medical Devices Agency (PMDA) required data from in vitro studies, PK study, and pharmacodynamics or clinical endpoint studies for drug development of generic nasal spray drug products. Until now, the MHLW has published guidelines and basic principles for topical drugs including cutaneous, dry powder inhaler, and ophthalmic products [3-5]. However, the MHLW has not published principles or guidelines for the approval of nasal generic drug products. Here, we present concrete data from the approval of the first generic Nasonex summarized from public information. Additionally, we compare the bioequivalence evaluations based on the generic version of Nasonex between Japan and the USA. 


\section{Data Package For First Generic Mometasone Furoate Nasal Suspension Spray Based On The Public Information In Japan}

\subsection{PK study}

The PK study aimed to evaluate the safety of mometasone furoate and was conducted using the plasma from 144 allergic rhinitis patients (reference: 72 subjects; test: 72 subjects). The plasma concentration of mometasone furoate 1 hour after administration was measured following administration of $200 \mu \mathrm{g}$ (total of four sprays of $50 \mu \mathrm{g}$, administered as two sprays into each nostril). The geometric mean concentrations of mometasone furoate in plasma were $8.85 \mathrm{pg} / \mathrm{mL}$ and $4.87 \mathrm{pg} / \mathrm{mL}$, and the maximum values were $24.5 \mathrm{pg} / \mathrm{mL}$ and $17.5 \mathrm{pg} / \mathrm{mL}$ for test and reference products, respectively. On the other hand, previously published data reported that the mean of mometasone furoate in plasma was between $126-334 \mathrm{pg} / \mathrm{mL}$ for inhalational mometasone furoate of $400-800$ $\mu \mathrm{g} /$ day at 14-day multiple dose study [6]. Based on these results, it was judged that there was not a significant difference for safety concerns between the test and reference products from inhalational mometasone furoate in the PK study, and also within previously published data.

\subsection{Clinical endpoint study}

A clinical endpoint study was conducted a randomized, evaluator-blinded, placebo-controlled, active- and placeboparallel-group study. A total of 180 patients with allergic rhinitis were enrolled (reference: 72 , test: 72 , and placebo: 36 subjects). The dosing regimen of two sprays into each nostril was administered daily for two weeks (total $200 \mu \mathrm{g}$ of four sprays of $50 \mu \mathrm{g}$ ). The primary efficacy endpoint was the change in total nasal symptom score (TNSS) from baseline (day -3 to -1 ) to two weeks (day 12 to 14 ). The therapeutic equivalence criterion for this study was predefined to be the $95 \%$ confidence interval $(\mathrm{Cl})$ for treatment differences within \pm 1.13 . This value was prespecified by the applicant due to the fact that 1.13 is half the value that was reported to be the change in TNSS from baseline to two weeks from a phase III study comparing innovator product and placebo, which was 2.27 [7]. The mean changes in TNSS from baseline to two weeks were $-4.3056,-4.5926$, and -1.9352 in test, reference, and placebo groups, respectively. The average estimate of mean change in TNSS was $0.342(95 \% \mathrm{Cl}-0.427$ to 1.112$)$, which satisfied the therapeutic equivalence criterion (Table 1).

Table 1

Results of total nasal symptom score from the therapeutic equivalence study

\begin{tabular}{|lcll|}
\hline TNSS & Test & Reference & Placebo \\
\hline Baseline $^{\mathrm{a}}$ & 8.764 & 8.685 & 8.861 \\
\hline Mean at two weeks $^{\mathrm{b}}$ & 4.458 & 4.093 & 6.926 \\
\hline Mean change from baseline & -4.3056 & -4.5926 & -1.9352 \\
\hline Differences $(95 \% \mathrm{Cl})$ & $0.342(-0.427$ to 1.112$)$ & \\
\hline TNSS: Total nasal symptom score; Cl: Confidence interval & \\
\hline a: Mean of Scores from Days -3 to -1 & & \\
\hline b: Mean of Scores from Days 12 to 14 & & \\
\hline
\end{tabular}




\section{Comparison Of Be Evaluations For The Generic Mometasone Furoate Nasal Suspension Spray Between Japan And The Usa.}

We have compared the BE evaluations in Japan and the USA for the generic mometasone furoate nasal suspension spray using data available on the package inserts, scientific articles published, and product specific guidance $[1,2$, 8]. We have summarized the data package of PK (Table 2) and clinical endpoint studies (Table 3).

Table 2

Comparison of pharmacokinetic studies with mometasone furoate nasal suspension spray between Japan and the USA

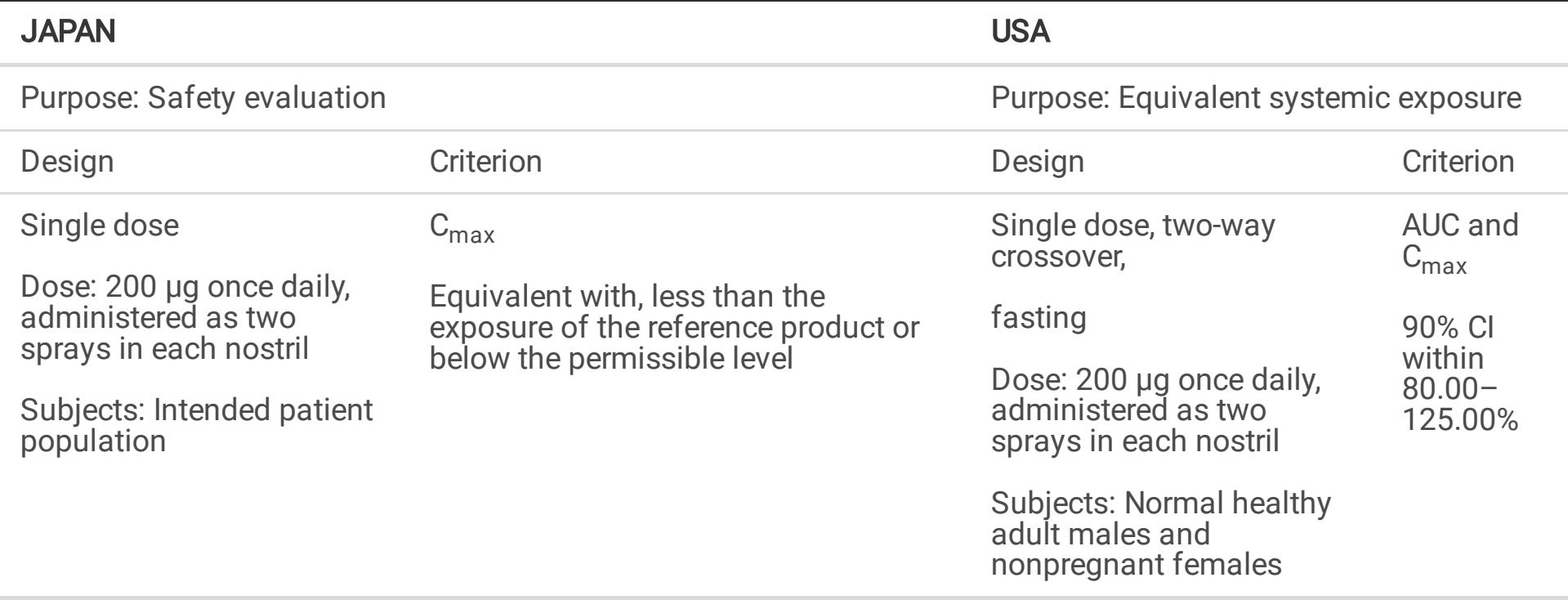

AUC: Area under the curve; Cl: Confidence interval

Table 3

Comparison of clinical endpoint studies with mometasone furoate nasal suspension spray in Japan and the USA

JAPAN USA

Design: Randomized, evaluator-blinded, three-arm, placebo-controlled, parallel group

Design: Randomized, double-blind, three-arm, placebocontrolled, parallel group

Subjects: Allergic rhinitis patients

Subjects: Allergic rhinitis patients

Dose: $200 \mu \mathrm{g}$ once daily, administered as two sprays into each nostril once daily

Dose: $200 \mu \mathrm{g}$ once daily, administered as two sprays into each nostril once daily

Primary endpoint: Change from baseline in TNSS at two weeks

Primary endpoint: Change from the baseline mean rTNSS to the treatment mean rTNSS

Criterion: 95\% Cl for treatment differences within $\pm 1.13$

Criterion: $90 \% \mathrm{Cl}$ within $80.00-125.00 \%$

TNSS: Total nasal symptom score; Cl: Confidence interval; rTNSS: reflective TNSS

Baseline mean rTNSS is the mean of the final seven scores from the placebo run-in period. The final 7 scores from the placebo run-in period consist of the AM and PM scores on Days $-3,-2$, and -1 and the AM score (prior to drug dosing) on Day 1 of the 14-day randomized treatment period.

Treatment mean rTNSS is the average of 27 scores from the randomized treatment period which consist of the PM score on Day 1 and the AM and PM scores on Days 2 to 14. 
Table 2 shows the comparison of PK study, and the study purposes are slightly different between Japan and the USA. Japan aims at safety evaluation, and the USA aims at equivalent assessment of systemic exposure. The study designs are also different: Japan evaluates allergic rhinitis patients on day 1 of a multiple dose study, while the USA conducts a single dose two-way crossover study with healthy volunteers under fasting conditions. Japan evaluates the plasma drug concentration at 1 hour after the first administration, while the USA evaluates the area under the curve and $\mathrm{C}_{\max }$ of the drug. The acceptance criteria are also different: Japan requires a concentration that was equivalent with, less than the exposure, or permissible level of the reference product, while the USA requires the results to fall within $90 \% \mathrm{Cl}$ of $80.00-125.00 \%$ for the ratios of the generic and innovator products.

In the clinical endpoint studies, the study design, subject, and dosages are the same in the studies from Japan and the USA (Table 3). However, the primary endpoints, 90 or $95 \% \mathrm{Cls}$, and therapeutic equivalence criteria are completely different. Japan uses the same primary endpoint as the endpoint for phase III trials for innovator products, while the USA scores the symptoms observed twice daily (AM and PM, 12 hours apart at the same times daily) throughout the 7-day placebo run-in period and the 14-day randomized treatment period. For this study, the scoring is done immediately prior to dosing (and 12 hours after the AM dose for once-daily dosing) to reflect the previous 12 hours (reflective scores). Japan generally adopts $95 \% \mathrm{Cl}$ to evaluate the therapeutic equivalence based on the index of clinical effects in the Q\&A 2 section of ICH E9 [9]. On the other hand, the USA accepts the same criterion of $90 \% \mathrm{Cl}$ within $80.00-125.00 \%$ for oral solid dosage forms. Japan adopts the half of the change from baseline in TNSS after two weeks based on the data of primary endpoint of phase III study between innovator product and placebo. This concept is mentioned in a domestic article which explain the ICH E10 [10], and in a concept paper from the EU that summarizes the margin of equivalence or noninferiority in comparative clinical trials [11]. Generally, Japan does not require a placebo-arm for $\mathrm{BE}$ evaluations. However, in this case, Japan also requires a placebo-arm because the test product has different pharmaceutical properties from the innovator product. It may be advised that a placebo-arm is added to clinical endpoint studies to establish a more sensitive and robust endpoint study in which the test and reference products can be accepted as statistically superior to the placebo.

\section{Conclusion}

We have summarized the clinical data that was published for the approval of the first generic mometasone furoate nasal spray suspension in Japan. In addition, we compared the BE evaluations and recommendations in Japan and the USA. The MHLW has previously published guidelines for the use of topical products, including cutaneous, dry powder inhaler, and ophthalmic products [3-5]. However, there have been no guidelines published regarding the BE of nasal products. We hope that the data summarized in this review can help establish basic principles or guidelines for BE evaluations of generic nasal products in the future.

\section{Declarations}

\section{Disclaimer}

The views expressed in this article are those of the authors and do not necessarily reflect the official views of the Pharmaceuticals and Medical Devices Agency.

\section{ETHICAL STATEMENT}

\section{Ethics approval and consent to participate}


Not Applicable.

\section{Consent for publication}

All authors consent for publication.

\section{Availability of data and materials}

Not Applicable.

\section{Competing interests}

Ryosuke Kuribayashi, Miho Kasuga, Kimika Kuwana, and Toru Yamaguchi declare that they have no conflict of interest that might be relevant to the contents of this article.

\section{Funding}

No external funding was used in the preparation of this manuscript.

\section{Author contributions}

R. K. was the main writer of this article. R.K., M.K., K.K and T.Y contributed to the fact-finding and editing of this article.

\section{Acknowledgements}

Not Applicable.

\section{References}

1. Package insert for Mometasone Nasal $50 \mu \mathrm{g}[\mathrm{MYL}] 56$ sprays and 112 sprays https://www.pmda.go.jp/PmdaSearch/iyakuDetail/ResultDataSetPDF/480115_1329710Q3020_1_02. Accessed 3 November 2021 (In Japanese).

2. Gotoh M, Sugita K, Saito A, Honda T, Hoashi K, Miyazaki T. A study of the therapeutic equivalence of generic vs mometasone nasal spray in patients with seasonal allergic rhinitis. Japanese Journal of Rhinology. 2018;57:716. https://www.jstage.jst.go.jp/article/jjrhi/57/1/57_7/_pdf/-char/ja. Accessed 3 November 2021 (In Japanese).

3. MHLW. Guideline for Bioequivalence Studies of Generic Products for Topical Use. http://www.nihs.go.jp/drug/be-guide(e)/Topical_BE-E.pdf. Accessed 7 November 2021.

4. MHLW. Basic Principles on Bioequivalence Evaluation of Generic Dry Powder Inhalers. https://www.nihs.go.jp/drug/be-guide(e)/Powder\%20Inhalers.pdf. Accessed 24 December 2021.

5. MHLW. Basic Principles on Bioequivalence Studies of Generic Ophthalmic dosage forms. https://www.nihs.go.jp/drug/be-guide(e)/Ophthalmic\%20dosage\%20forms.pdf. Accessed 24 December 2021.

6. Review report of PMDA for Asmanex Twisthaler $100 \mu \mathrm{g} 60$ doses and $200 \mu \mathrm{gg} 60$ doses https://www.pmda.go.jp/drugs/2009/P200900030/170050000_22100AMX01819000_A100_1.pdf. Accessed 3 November 2021 (In Japanese). 
7. Common technical document 2.7.6.5.1.2.2 for Nasonex https://www.pmda.go.jp/drugs/2008/P200800030/index.html. Accessed 3 November 2021 (In Japanese).

8. Product specific guidance for mometasone furoate https://www.accessdata.fda.gov/drugsatfda_docs/psg/PSG_020762.pdf. Accessed 7 November 2021

9. ICH E9 Q\&A. Statistical principles for clinical trials https://www.pmda.go.jp/files/000156112.pdf. Accessed 7 November 2021 (In Japanese)

10. Morikawa T, Ono S. ICH E10 guidelines for the choice of control group. IYAKUHIN KENKYU. 2001;32:98-108. (In Japanese).

11. The European Agency for the Evaluation of Medicinal Products. Concept paper on the development of a committee for proprietary medicinal products (CPMP) points to consider on biostatistical/methodological issues arising from recent CPMP discussions on licensing applications: Choice of delta. September 1999. http://www.f-mri.org/upload/articles-for-Feldmann-et-Dubanchet-PART-11/STAT-CHMP2158-Delta-choice.pdf. Accessed 7 November 2021

\section{Supplementary Files}

This is a list of supplementary files associated with this preprint. Click to download.

- GraphicalAbstract.jpg 